\title{
Decontamination of Shell-Eggs with Pulsed UV-Light
}

\section{Nene M. Keklik}

Department of Agricultural and Biological Engineering, The Pennsylvania State University, University Park, PA 16802, nmk174@psu.edu

\section{Ali Demirci}

Department of Agricultural and Biological Engineering, The Pennsylvania State University, University Park, PA 16802, demirci@psu.edu

\section{Paul H. Patterson}

Department of Poultry Science, The Pennsylvania State University, University Park, PA 16802, php1@psu.edu

\section{Virendra M. Puri}

Department of Agricultural and Biological Engineering, The Pennsylvania State University, University Park, PA 16802, v7p@psu.edu

\author{
Written for presentation at the \\ 2009 ASABE Annual International Meeting \\ Sponsored by ASABE \\ Grand Sierra Resort and Casino \\ Reno, Nevada \\ June 21 - June 24, 2009
}




\begin{abstract}
Currently, most methods used by the food industry to decontaminate shell-eggs involve washing the egg surface with various chemical solutions. In this study, the effectiveness of pulsed UV-light was evaluated for the decontamination of shell-eggs. Samples inoculated with Salmonella Enteritidis on top surface on the equator were treated with pulsed UV-light for 1, 3, 5, 10, 15, 20, and 30 seconds at 9.5 and $14.5 \mathrm{~cm}$ from the UV-strobe in a chamber. An input voltage of $3,800 \mathrm{~V}$ was used to generate a $1.27 \mathrm{~J} / \mathrm{cm}^{2} /$ pulse of radiant energy at $1.5 \mathrm{~cm}$ below the lamp surface, producing a polychromatic radiation in the wavelength range of 100 to $1100 \mathrm{~nm}$, with $54 \%$ of the energy being in the UV-light region. Log reductions in microbial population were determined after treatments. A maximum $\log _{10}$ reduction of $5.3\left(\mathrm{CFU} / \mathrm{cm}^{2}\right)$ was obtained after 20-s treatment at $9.5 \mathrm{~cm}$ without any visual damage to the egg. The temperature and total energy absorbed at each treatment condition was determined using a $K$-type thermocouple and a radiometer, respectively. Temperature and energy increased with higher treatment time and shorter distance from the UV-lamp. A maximum temperature increase of $10.5 \pm 1.6^{\circ} \mathrm{C}$ and a maximum energy of $35.3 \pm 0.1 \mathrm{~J} / \mathrm{cm}^{2}$ were observed after 30 -s treatment at $9.5 \mathrm{~cm}$. This study demonstrated that pulsed UV-light has potential to decontaminate shell-egg surfaces.
\end{abstract}

Keywords. shell-egg, pulsed ultraviolet light, decontamination, Salmonella Enteritidis

\title{
Introduction
}

Salmonellosis associated with eggs is a significant public health problem in the United States and some of the European countries (CDC, 2005). Salmonella Enteritidis is the main causative pathogen of salmonellosis related to eggs. Salmonella is either horizontally or vertically transferred to eggs. Horizontal transmission is the contamination of egg from another contaminated source while vertical transmission is the contamination of egg from infected hen during formation of ovaries. About $80 \%$ of human outbreaks were related to the consumption of eggs or egg containing foods from Salmonella Enteritidis outbreaks during the period from 1985 to 1999 (Gast, 2006). Other microorganisms associated with shell-egg surfaces are Yersinia enterocolitica, Escherichia coli O157:H7, and Campylobacter jejuni (Erdogrul, 2004; USDA, 2001a).

Eggs naturally have four layers of protection which prevent bacteria from reaching the yolk: the shell, inner and outer membranes between the shell and the albumen, the albumen (eggwhite), and the vitelline (yolk) membrane. Furthermore, the cuticle, a membrane-like substance covers the egg-shell on the outside. The cuticle seals the pores of the egg-shell and prevents bacteria from penetrating into the egg. However, the cuticle can easily be damaged during the washing process. Some egg processors cover the egg surfaces with an extra thin layer of edible oil after they are washed to replace the damaged cuticle (FSIS \& FDA, 1998).

Generally, eggs are washed in a detergent bath on conveyor rollers while being cleaned with brushes. The USDA mandates the egg washing practice for all USDA-grade eggs. The Food Safety Inspection Service (FSIS) and the Food and Drug Administration (FDA) are both responsible for egg safety (CFSAN, 2000). These agencies and the egg industry have been investigating alternative decontamination techniques which could serve the public, minimize costs and benefit both the public and the industry.

Different techniques have been studied and evaluated for the decontamination of egg surfaces. One of the most effective techniques is the use of noxious chemicals or fumigation (Davies and Breslin, 2003). Chlorine, iodine, hydrogen peroxide, and ozonated water are among the disinfectants used 
for the decontamination of eggs surfaces. However, these agents are only partially effective. Treatment of eggs with hot water at $80-100^{\circ} \mathrm{C}$ is another effective method (Davies and Breslin, 2003), though, may result in cooking of the egg white or cracking of the egg-shell.

Bialka et al. (2004) studied the efficacy of electrolyzed oxidizing water to decontaminate Escherichia coli K12 and Salmonella Enteritidis loads on shell-eggs surfaces. For typical detergent-sanitizer treatments, 1.7 and 2.0 log reduction were observed for $S$. Enteritidis and E.coli K12, respectively, while 2.1 and 2.3 log reductions were observed for S. Enteritidis and E.coli K12 after treatment with EO water.

Higgins et al. (2005) studied the disinfection of table eggs by ionized reactive oxygen species using Binary lonization Technology (BIT). Table eggs were treated with BIT spray for $5 \mathrm{~s}$. The log reduction obtained was 7.77. They also found that this treatment did not have a significant effect on the hatchability of eggs.

Ultraviolet light has also been studied for the decontamination of egg surfaces. In the study of De Reu et al. (2006), the effect of UV light on the microbial load of shell egg surfaces was evaluated. The eggs were treated on a double roller conveyor belt with standard UV light $(254 \mathrm{~nm})$ at an intensity of $10 \mathrm{~mW} / \mathrm{cm}^{2}$. Escherichia coli and Staphylococcus aureus were used for inoculum. Log reductions were 3-4 log CFU obtained for both microorganisms by UV treatment for 4.7 and $18.8 \mathrm{~s}$, respectively. The natural bacterial load of uninoculated shell-eggs was reduced from 4.47 to 3.57 log by standard UV treatment of $4.7 \mathrm{~s}$. The UV treatment did not affect the internal bacterial contamination of shell eggs.

Pulsed UV-light is a novel decontamination technology, which offers effective inactivation of pathogens on the food surfaces in very short periods of time. In 1999, pulsed light treatment of food was approved by FDA (Federal Register, 1999). Basically, a pulsed UV-light lamp produces a continual broadband spectrum from the deep UV to infrared. This continual spectrum is especially rich and efficient in the UV range below $400 \mathrm{~nm}$, which is germicidal.

In this study, the effectiveness of pulsed UV-light as a novel intervention method was evaluated on the Salmonella Enteriditis population on shell-eggs. The temperature profile of the samples during treatments and energy absorbed at each treatment condition were also determined.

\section{Materials and Methods}

\section{Microorganism}

Salmonella Enteritidis phage type 8 (PT8) was obtained from the Salmonella Center at the University of Pennsylvania. The culture was maintained on tryptic soy agar (TSA; Difco, Detroit, MI) supplemented with $0.6 \%$ yeast extract (TSAYE; Difco, Detroit, MI).

To eliminate any other microorganisms that may be present, antibiotic-resistant Salmonella Enteritidis cultures were prepared as described by Catalano and Knabel (1994). Briefly, S. Enteritidis PT8 was grown in $10 \mathrm{ml}$ of tryptic soy broth (TSB; Difco, Detroit, MI) supplemented with $0.6 \%$ yeast extract (TSBYE) for $24 \mathrm{~h}$ at $37^{\circ} \mathrm{C}$. Then a loopful portion was streaked onto slants of tryptic soy agar supplemented with $0.6 \%$ yeast extract (TSAYE) and the slants were incubated for $24 \mathrm{~h}$ at $37^{\circ} \mathrm{C}$. After the incubation, colonies were picked and streaked onto TSAYE plates with $100 \mu \mathrm{g} / \mathrm{ml}$ nalidixic acid (TSAYE-N; Fisher Scientific Co., Fair Lawn, NJ), and incubated at $37^{\circ} \mathrm{C}$ for $24 \mathrm{~h}$. Then, the surviving cells were picked and plated onto TSAYE-N and incubated for $24 \mathrm{~h}$ at $37^{\circ} \mathrm{C}$. At the end of the fifth subsequent plating, the isolated colonies were maintained in TSBYE containing $100 \mu \mathrm{g} / \mathrm{ml}$ nalidixic acid (TSBYE-N). One $\mathrm{ml}$ of this culture was inoculated into $10 \mathrm{ml}$ TSBYE-N and incubated for $24 \mathrm{~h}$ at 
$37^{\circ} \mathrm{C}$. Then, a loopful portion was streaked onto TSAYE plates containing $100 \mu \mathrm{g} / \mathrm{ml}$ of both nalidixic acid and streptomycin sulfate (TSAYE-NS; Sigma-Aldrich, St. Louis, MO), and incubated at $37^{\circ} \mathrm{C}$ for $24 \mathrm{~h}$. After the incubation, the surviving cells were picked and plated onto TSAYE-NS and incubated at $37^{\circ} \mathrm{C}$ for $24 \mathrm{~h}$. At the end of the fifth subsequent plating, the isolated colonies (spontaneous mutants) were isolated and named as S. Enteritidis PT8NSR (nalidixic acid and streptomycin sulfate resistant). This antibiotic-resistant strain was stored at $-80^{\circ} \mathrm{C}$ in $20 \%$ glycerol solution and maintained on TSAYE-NS slant at $4^{\circ} \mathrm{C}$, which was sub-cultured biweekly to maintain viability.

\section{Preparation of inoculum}

Salmonella Enteritidis PT8NSR was grown in $100 \mathrm{ml}$ tryptic soy broth with $0.6 \%$ yeast extract (TSBYE) for $24 \mathrm{~h}$ at $37^{\circ} \mathrm{C}$, and then centrifuged for $30 \mathrm{~min}$ at $3,300 \times \mathrm{g}$ and $10^{\circ} \mathrm{C}$. At the end of the centrifugation, the supernatant was discarded. Cells were then washed with sterile $0.1 \%$ peptone water and centrifuged for $30 \mathrm{~min}$ at $3,300 \times \mathrm{g}$ and $10^{\circ} \mathrm{C}$. After discarding the supernatant, cells were re-suspended in $10 \mathrm{ml}$ of $0.1 \%$ peptone water, which yielded approximately $10^{9} \mathrm{CFU} / \mathrm{ml}$.

\section{Inoculation of shell-eggs}

Eggs from W-36 Hyline hens that are 32 weeks old were obtained from the Pennsylvania State University Poultry Education and Research Center (PERC). Eggs were held at room temperature for $2 \mathrm{~h}$ before an experiment. An area of $2 \times 1 \mathrm{~cm}^{2}$ on top surface on the equator of each egg was inoculated with $0.1 \mathrm{ml}$ of prepared inoculum solution of $S$. Enteritidis PT8NSR to obtain pathogen levels of approximately 5-6 $\log _{10}$ CFU on the surface. The samples were kept under laminar flow in a biological hood for 30 minutes before treatments to facilitate the attachment of microbial cells to sample surfaces.

Only the top surfaces were inoculated, because the pulsed UV-light chamber was equipped with one lamp on the top (Figure 1). In order to expose all the surfaces, samples had to be rotated, which would make the execution of the trials harder. Therefore, samples were exposed to pulsed UV-light only on the top surface without any rotation.

\section{Pulsed UV-light system}

Pulsed UV-light was applied to shell-eggs using the SteriPulse-XL $® 3000$ Pulsed UV-Light System (XENON Corporation, Wilmington, MA) (Figure 1). The system included a laboratory test chamber $(0.64 \mathrm{~m} \times 0.15 \mathrm{~m} \times 0.19 \mathrm{~m})$ and several shelf settings, which allowed treatment of eggs at varying distances from the lamp. The UV lamp pulsed three times per second. Each pulse's duration was $360 \mu \mathrm{s}$. An input voltage of $3,800 \mathrm{~V}$ was used to generate $1.27 \mathrm{~J} / \mathrm{cm}^{2} /$ pulse of radiant energy at 1.5 $\mathrm{cm}$ below the lamp surface. With this energy, a polychromatic radiation was produced in the wavelength $1100 \mathrm{~nm}$, with energy being in region et al., 2007). range of 100 to $54 \%$ of the the UV-light (Krishnamurthy

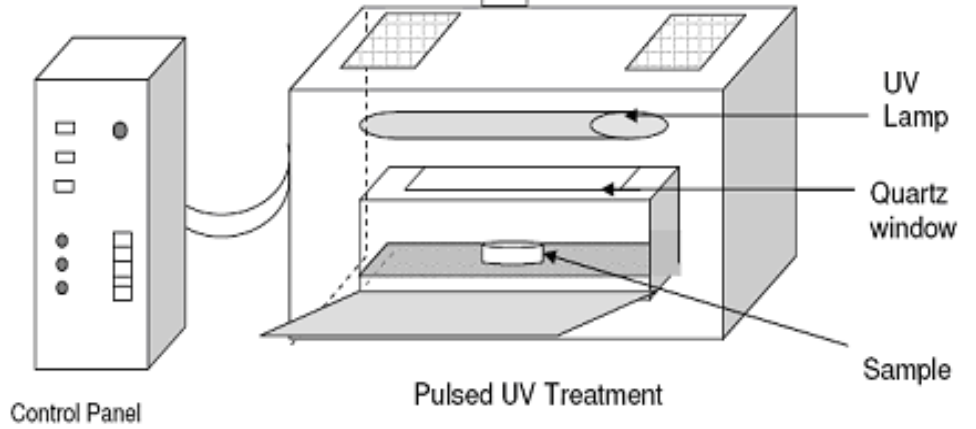


Figure 1. Schematic diagram of the pulsed UV-light treatment system

(Bialka, 2007)

\section{Treatment with pulsed UV-light}

Each inoculated sample was placed on the middle of the shelf in the pulsed UV-light chamber (Figure 1). The number of pulses (duration) and the distance between the sample and the quartz window were selected to be the system variables. Accordingly, the samples were treated for $1,3,5$, $10,15,20$, and 30 seconds at 9.5 and $14.5 \mathrm{~cm}$ from the UV-strobe in the pulsed UV-light chamber.

\section{Energy and temperature monitoring}

During the pulsed UV-light treatments, temperatures of shell-egg samples were monitored using a type K thermocouple (Omegaette HH306, Omega Eng. Inc., Stamford, CT) for up to 30 s by inserting the thermocouple into a depth of $2-3 \mathrm{~mm}$ through a $1.45-\mathrm{mm}$ hole drilled from the top surface of the samples. The amount of energy received at each distance from the UV-strobe in the pulsed UV-light chamber was measured by Nova Laser Power energy monitor (Ophir Optronics Ltd., Wilmington, MA), which averaged the energy level over 9 pulses. The amount of energy was calculated and expressed in $\mathrm{J} / \mathrm{cm}^{2}$ for each treatment condition.

\section{Microbiological analysis}

Each treated or untreated sample was transferred to a plastic bag with $25 \mathrm{ml}$ of $0.1 \%$ peptone water rinse solution, and shaken for 1 minute. The peptone water in the bag corresponding to each egg was then serially diluted in $0.1 \%$ peptone water (Difco, Detroit, MI). The dilutions were spiral-plated onto plates of TSAYE-NS agar by using an autoplater (Autoplate 4000, Spiral Biotech, Norwood, MA). The plates were then incubated at $37^{\circ} \mathrm{C}$ for $24 \mathrm{~h}$. Finally, S. Enteritidis PT8NSR colonies were counted using an autocounter (Q-Count, Version 2.1, Spiral Biotech, Norwood, MA). The counts were expressed as CFU $/ \mathrm{cm}^{2}$ of sample surface. Typical Salmonella colonies were confirmed serologically using a Salmonella agglutination latex assay (Remel, Lenexa, KS) and gram-staining.

To ensure detection of low levels of pathogens after treatments, samples that demonstrated zero plate counts were enriched. Enrichments were done by transferring $1 \mathrm{~mL}$ of the peptone water rinse solution to $9 \mathrm{~mL}$ of TSBYE or TT Broth Base Hajna (Difco, Detroit, MI). After incubating the TSBYE broth at $37^{\circ} \mathrm{C}$ for $24 \mathrm{~h}$, and the TT Broth Base Hajna at $45^{\circ} \mathrm{C}$ for $48 \mathrm{~h}$; a loop of each enrichment broth was streaked onto xylose lysine desoxycholate (XLD) agar, and incubated for $24 \mathrm{~h}$ at $37^{\circ} \mathrm{C}$ (Bialka et al., 2004). Salmonella colonies were confirmed serologically using the Salmonella 
agglutination latex assay. The minimum detection limit of $1.3 \log _{10}$ (CFU/ml rinse solution) was subtracted from the initial $\log _{10}(\mathrm{CFU} / \mathrm{ml}$ rinse solution) number when plates with zero colonies were observed.

\section{Statistical analysis}

Each treatment was replicated in triplicate. Samples which were not treated in the pulsed UV-light chamber were used as control. The microbial reductions were analyzed by using ANOVA - General Linear Model using MINITAB (Version 14) (MINITAB Inc, State College, PA). The significant differences in mean values were determined using Tukey's method at the $95 \%$ confidence interval.

\section{Results and Discussion}

The effectiveness of pulsed UV-light was evaluated by determining the $\log _{10}$ reduction of Salmonella Enteritidis PT8NSR population on the shell-egg surface. Total energy and temperature increase of samples were determined for each treatment condition by a radiometer and a K-type thermocouple, respectively.

\section{Log reductions}

The log reductions of Salmonella Enteritidis PT8NSR inoculated on the $2 \times 1 \mathrm{~cm}$ area on top surface of shell-egg samples were determined at treatment times of $1,3,5,10,15,20$, and 30 seconds at 9.5 and $14.5 \mathrm{~cm}$ from the UV-strobe in the pulsed UV-light chamber.

Log reductions of $S$. Enteritidis PT8NSR after treatments are given in Table 1. At a treatment distance of $9.5 \mathrm{~cm}$ from the UV-strobe, the reduction was between 2.0 and $5.3 \mathrm{CFU} / \mathrm{cm}^{2}$ and the visual appearance of samples (before/after cracking) did not show any difference after treatments. Treatments for $1 \mathrm{~s}$ and $3 \mathrm{~s}$ were not significantly different ( $p>0.05)$. Treatments for 3,5 , and 10-s were not significantly different $(p>0.05)$, while 10 -s treatment was not significantly different $(p>0.05)$ from 15-s treatment. The treatments for 20 and 30-s were significantly different $(p<0.05)$ from other treatments.

At $14.5 \mathrm{~cm}$, the reduction ranged from 1.3 to $5.3 \mathrm{CFU} / \mathrm{cm}^{2}$ and the visual appearance of samples (before/after cracking) did not change after treatments. Treatments for 1 and $3 \mathrm{~s}$ were significantly different $(p<0.05)$, while 3-s and 5 -s treatments were not significantly different $(p>0.05)$. Treatment for $5 \mathrm{~s}$ was not significantly different $(p>0.05)$ from 10-s treatment, while 10-s treatment was not significantly different $(p>0.05)$ from 15 -s treatment. Treatments for 20 and 30 s were significantly different $(p<0.05)$ from other treatments.

Table 1. Log reductions of Salmonella Enteritidis PT8NSR on shell-eggs ${ }^{1}$.

\begin{tabular}{|c|c|c|}
\hline \multirow{2}{*}{ Treatment Time (s) } & \multicolumn{2}{|c|}{ Log Reduction $\left(\mathrm{CFU} / \mathrm{cm}^{2}\right)$} \\
\cline { 2 - 3 } & at $9.5 \mathrm{~cm}$ & at $14.5 \mathrm{~cm}$ \\
\hline
\end{tabular}




\begin{tabular}{|c|c|c|}
\hline 1 & $2.0 \pm 0.3 \mathrm{~A}$ & $1.3 \pm 0.3 \mathrm{~A}$ \\
\hline 3 & $2.8 \pm 0.1 \mathrm{AB}$ & $2.3 \pm 0.4 \mathrm{~B}$ \\
\hline 5 & $3.2 \pm 0.2 \mathrm{~B}$ & $2.7 \pm 0.3 \mathrm{BC}$ \\
\hline 10 & $3.5 \pm 0.5 \mathrm{BC}$ & $3.2 \pm 0.1 \mathrm{CD}$ \\
\hline 15 & $4.0 \pm 0.3 \mathrm{C}$ & $3.4 \pm 0.1 \mathrm{D}$ \\
\hline 20 & $\geq 5.3 \pm 0.3 \mathrm{D}^{2,3}$ & $\geq 5.3 \pm 0.0 \mathrm{E}^{2,4}$ \\
\hline 30 & $\geq 5.3 \pm 0.3 \mathrm{D}^{2,3}$ & $\geq 5.3 \pm 0.0 \mathrm{E}^{2,4}$ \\
\hline
\end{tabular}

${ }^{1}$ Within the same column, values not followed by the same letter are significantly different $(p<0.05)$.

${ }^{2}$ Plates with zero colonies were observed. The minimum detection limit was subtracted from the initial $\log _{10}$ population to determine the $\log _{10}$ reduction.

${ }^{3}$ The enrichments were negative.

${ }^{4}$ The enrichments were positive.

The treatments at 9.5 and $14.5 \mathrm{~cm}$ were not significantly different $(p>0.05)$ regardless of the treatment times. Based on these findings, the optimum treatment condition was identified as 20-s treatment at $9.5 \mathrm{~cm}$, which was the treatment with the shortest treatment time that resulted in negative enrichments. Accordingly, the optimum treatment of samples yielded ca. $5.3 \log _{10}$ reduction (CFU/cm²), which corresponds to about $99.999 \%$ reduction.

\section{Energy and temperature measurements}

When the distance between the UV-strobe and top surface of egg samples was $9.5 \mathrm{~cm}$, the total amount of energy obtained at the level of the top surface of egg samples ranged from 1.2 to 35.3 $\mathrm{J} / \mathrm{cm}^{2}$ after the 1 -s and 30 -s treatment, respectively. The initial temperature of samples was $16.7 \pm 0.4^{\circ} \mathrm{C}$, and the temperature difference between the treated and untreated (initial) samples ranged from 0.5 to $10.5^{\circ} \mathrm{C}$ after $1-\mathrm{s}$ and 30 -s treatment, respectively (Table 2).

When the distance between the UV-strobe and top surface of egg samples was $14.5 \mathrm{~cm}$, the total amount of energy obtained at the level of the top surface of egg samples ranged from 0.8 to 24.8 $\mathrm{J} / \mathrm{cm}^{2}$ after 1 -s and 30 -s treatment, respectively. The initial temperature of samples was $17.6 \pm 0.1{ }^{\circ} \mathrm{C}$. The temperature increase of samples ranged from 0.2 to $7.8^{\circ} \mathrm{C}$ after 1 -s and 30 -s treatment, respectively.

Table 2. Energy and temperature changes during pulsed UV-light treatments of shell-eggs.

Treatment Time

(s)
Total Energy $\left(\mathrm{J} / \mathrm{cm}^{2}\right)$ 


\begin{tabular}{|c|c|c|}
\hline & $9.5-\mathbf{c m}$ Distance & 14.5-cm Distance \\
\hline 1 & $1.2 \pm 0.0$ & $0.8 \pm 0.0$ \\
\hline 3 & $3.5 \pm 0.0$ & $2.5 \pm 0.0$ \\
\hline 5 & $5.9 \pm 0.0$ & $4.1 \pm 0.0$ \\
\hline 10 & $11.8 \pm 0.0$ & $8.3 \pm 0.0$ \\
\hline 15 & $17.7 \pm 0.1$ & $12.4 \pm 0.1$ \\
\hline 20 & $23.6 \pm 0.1$ & $16.5 \pm 0.1$ \\
\hline 30 & $35.3 \pm 0.1$ & $24.8 \pm 0.1$ \\
\hline & Temperature increase $\left(\mathrm{T}-\mathbf{T}_{\text {initial }}\right)$ & $\left.{ }^{\circ} \mathrm{C}\right)$ \\
\hline 1 & $0.5 \pm 0.4$ & $0.2 \pm 0.0$ \\
\hline 3 & $1.9 \pm 0.9$ & $0.9 \pm 0.4$ \\
\hline 5 & $3.4 \pm 1.3$ & $2.0 \pm 0.8$ \\
\hline 10 & $5.7 \pm 1.1$ & $3.5 \pm 0.7$ \\
\hline 15 & $6.9 \pm 0.9$ & $4.5 \pm 0.6$ \\
\hline 20 & $8.1 \pm 0.6$ & $5.6 \pm 0.7$ \\
\hline 30 & $10.5 \pm 1.2$ & $7.8 \pm 1.1$ \\
\hline
\end{tabular}

Total energy absorbed by the radiometer and temperature change of samples increased with longer treatment time and shorter distance from the UV-strobe. The instantaneous energy $\left(\mathrm{J} / \mathrm{pulse} / \mathrm{cm}^{2}\right)$ was accumulated over time, resulting in a higher total energy $\left(\mathrm{J} / \mathrm{cm}^{2}\right)$ absorbed by the radiometer at the same distance from the UV-strobe. On the contrary, total energy received $\left(\mathrm{J} / \mathrm{cm}^{2}\right)$ decreased with longer distance from the UV-strobe for the same treatment time, which is the expected case according to the inverse square law (VanOsdell and Foarde, 2002).

Temperature change increased with longer treatment time at the same distance from the UV-strobe, which is most likely due to the generation of more heat by the UV-strobe during longer treatment times. On the other hand, temperature change decreased with longer distance from the UV-strobe for the same treatment time.

\section{Conclusions}

The findings of this study indicate that pulsed UV-light was effective in reducing the population of Salmonella Enteritidis PT8NSR on the surfaces of shell-eggs. The optimum treatment was 20-s at $9.5 \mathrm{~cm}$ from the UV-strobe, which resulted in ca. $5.3 \log _{10} \mathrm{CFU} / \mathrm{cm}^{2}$ reduction or $99.999 \%$ reduction without any visual damage on the samples.

Energy and temperature of samples increased with longer treatment time and closer distance the UV-lamp. The maximum energy $\left(35.3 \pm 0.1 \mathrm{~J} / \mathrm{cm}^{2}\right)$ was observed after $30 \mathrm{~s}$ treatment at $9.5 \mathrm{~cm}$. The energy level obtained at the optimum condition was $23.6 \pm 0.1 \mathrm{~J} / \mathrm{cm}^{2}$. A maximum temperature increase of $10.5 \pm 1.2^{\circ} \mathrm{C}$ was observed after $30 \mathrm{~s}$ treatment at $9.5 \mathrm{~cm}$. The temperature change observed at the optimum condition was $8.1 \pm 0.6^{\circ} \mathrm{C}$. 
In the future, the effect of pulsed UV-light on the quality of shell-eggs including albumen height, eggshell strength, and presence of cuticle will be evaluated.

\section{Acknowledgments}

The pulsed UV-light system was obtained with funds from the NASA Food Technology Commercial Space Center equipment grant. We would like to thank Xenon Corporation for providing the pulsed UV-light system, and the Poultry Education and Research Center (PERC) at The Pennsylvania State University for providing the shell-eggs.

\section{References}

1. Bialka K. L., A. Demirci, S. J. Knabel, P. H. Patterson, and V. M. Puri. 2004. Efficacy of electrolyzed oxidizing water for the microbial safety and quality of eggs. J. Poultry Sci. 83: 20712078.

2. Bialka K. L. and A. Demirci. 2007. Decontamination of Escherichia coli O157:H7 and Salmonella enterica on blueberries using ozone and pulsed UV-light. J. Food Sci. 72(9): M391-M396.

3. Catalano, C. R., and S. J. Knabel. 1994. Incidence of Salmonella in Pennsylvania egg processing plants and destruction by high pH. J. Food. Prot. 57: 587-591.

4. CDC. 2005. Salmonella enteritidis. National Center for Immunization and Respiratory Diseases: Division of Bacterial Diseases. Available at: http://www.cdc.gov/ncidod/dbmd/diseaseinfo/salment_g.htm. Accessed 26 April 2009.

5. CFSAN. 2000. U.S. Egg Safety Action Plan. Rockville, Md.: FDA. Available at: http://www.cfsan.fda.gov/ dms/fs-eggs3.html. Accessed 06 March 2007.

6. Davies, R. H., and M. Breslin. 2003. Investigations into possible alternative decontamination methods for Salmonella Enteritidis on the surface of table eggs. J. Vet. Med. B. 50: 38-41.

7. De Reu, K., K. Grijspeerdt, L. Herman, M. Heyndrickx, M. Uyttendaele, J. Debevere, F. F. Putirulan, and N. M. Bolder. 2006. The effect of a commercial UV disinfection system on the bacterial load of shell eggs. Letters in Applied Microbiology 42: 144-148.

8. Erdogrul, O. 2004. Listeria monocytogenes, Yersinia enterocolitica and Salmonella Enteritidis in Quail Eggs. Turk. J. Vet. Anim. Sci. 28: 597-601.

9. Federal Register. 1999. Pulsed light treatment of food. Fed. Regist. 66: 338829-338830.

10. FSIS \& FDA. 1998. Salmonella Enteritidis in Eggs. Federal register 63(96): 27502-27511. Available at: http://www.cfsan.fda.gov/ Ird/fr980519.html. Accessed 06 March 2007.

11. Gast, R. K. 2006. Salmonella in eggs: issues and research. Egg Safety and Quality Research Unit, Agricultural Research Service, USDA, Abstract. Athens, Ga.: Russel Research Center.

12. Higgins, S. E., A. D. Wolfenden, L. R. Bielke, C. M. Pixley, A. Torres-Rodriguez, J. L. Vicente, D. Bosseau, N. Neighbor, B. M. Hargis, and G. Tellez. 2005. Application of ionized reactive oxygen species for disinfection of carcasses, table eggs, and fertile eggs. J. Appl. Poult. Res. 14: 716720. 
13. Krishnamurthy K., J. C. Tewari, J. Irudayaraj, and A. Demirci. 2007. Microscopic and spectroscopic evaluation of inactivation of Staphylococcus aureus by pulsed UV-light and infrared heating. Food Bioprocess Technol. (Available online). DOI 10.1007/s11947-008-0084-8.

14. USDA. 2001. Economics of Foodborne Disease: Food and Pathogens. Economic Research Service. Available at:

http://www.ers.usda.gov/Briefing/FoodborneDisease/foodandpathogens.htm. Accessed 06 March 2007.

15. VanOsdell D. and K. Foarde. 2002. Defining the effectiveness of UV lamps installed in circulating air ductwork. ARTI-21CR/610-40030-01. Arlington, VA: Air-Conditioning and Refrigeration Technology Institute. Available at: http://www.arti21 cr.org/research/completed/finalreports/40030final.pdf. Accessed 15 May 2008. 